\title{
The Research on the Functions of Universities in an Innovation Cluster and the Realization Mechanisms
}

\author{
Dan Zhou \\ Institute of Economy and Finance, Xidian University, Xi'an, China \\ Email: slify@sina.com
}

How to cite this paper: Zhou, D. (2017) The Research on the Functions of Universities in an Innovation Cluster and the Realization Mechanisms. Open Journal of Business and Management, 5, 63-72. http://dx.doi.org/10.4236/ojbm.2017.51006

Received: December 2, 2016

Accepted: December 20, 2016

Published: December 23, 2016

Copyright $\odot 2017$ by author and Scientific Research Publishing Inc. This work is licensed under the Creative Commons Attribution International License (CC BY 4.0).

http://creativecommons.org/licenses/by/4.0/

\begin{abstract}
University is one of the most important innovation subjects in innovation clusters and also the headstream of innovation. Theoretical research and practice indicate that the functions of universities in an innovation cluster cannot be ignored. With a series of policies to improve innovation ability of the universities in China approved, how to stimulate universities to play their role in innovation clusters becomes a research hotspot both in academic circles and policy community. However, its primary premise is to make clear the real role that universities play in an innovation cluster. Therefore, we put forward the functions of universities in an innovation cluster including knowledge production, knowledge propagation and innovation culture advocate, then study the realization mechanism of the functions in order to guide universities to play the role in an innovation cluster better.
\end{abstract}

\section{Keywords}

University, Innovation Cluster, Function, Realization Mechanism

\section{Introduction}

Although the expressions about the concept of innovation cluster have differences, scholars all agree that an innovation cluster is a technical economy network that forms surrounding industry chain, value chain and knowledge chain and is made of different subjects, including enterprises, universities, government and so on. Its characteristics are agglomeration economy and a huge amount of knowledge spillover.

At present, the research of innovation cluster focuses on its concept, law of development and practice exploration. However, the research of subjects in an innovation cluster is mainly including the research of enterprises and government in an innovation cluster. It often ignores the research of universities in an innovation cluster. As a result, this research makes the functions of universities in an innovation cluster as the topic. 
All in all, in the following sections, the second part briefly discusses the significance of this research. The third part mainly introduces the three functions of universities in an innovation cluster, including knowledge production, knowledge propagation and advocate for innovation culture. Then the fourth part, fifth part and sixth part respectively discuss their realization mechanisms. The last part puts forward the conclusions and implications.

\section{Research Significance}

During the era of knowledge economy, innovation becomes the key factor to drive the development of economy. As a simplified form of national innovation system, the development of innovation clusters is closely connected with the formation of the national core competitive advantages. So cultivating innovation clusters becomes an important carrier and a powerful gripper for developing countries to catch up with developed countries and construct innovative countries.

University is one of the key subjects in an innovation cluster, and makes a difference to breeding an innovation cluster. The practice about innovation clusters confirms this point, for example, the innovation cluster under the "Korean mode" ignored extremely universities' functions of knowledge creation and knowledge spillover, and it causes Korea is in the dock in the current economic development [1]. However, the breeding of innovation cluster under the "American mode" attaches great importance to the function of universities as a main body, and make them play the role of knowledge center, as a result, they show strong vitality in promoting regional economic development.

Therefore, if we would like to make universities play their role well, we must be clear about their functions and realization mechanisms in an innovation cluster. But in the theoretical research on it now, scholars in universities pay their attention to research related mainly with interaction between industry and university. And at the same time, universities of innovation clusters in China still only work in the shallow level of knowledge processing simply and knowledge spreading inefficiently, and not become an important part of the whole collaborative process of the cluster innovation. Why innovation cluster both in theory research and practice in China has limits is that we cannot realize the real role of universities in innovation clusters.

In order to help universities solve their problems in innovation clusters, and guide them to make sure their location in clusters, so that they can realize their value in innovation clusters better, and release full energy in driving innovation clusters to be stronger, this passage has studied the functions of universities in an innovation cluster and their realization mechanisms through theory analysis on university and innovation cluster.

\section{The Functions of Universities in an Innovation Cluster}

After a long period of development and evolution for universities, the main functions of the modern university are including talent training, scientific research, social services and cultural inheritance and innovation [2] [3]. A lot of practices and theoretical researches show that the university plays a decisive role in the development of innovative 
clusters.

As a new organizational form of integration of science and economy in the modern time, an innovation cluster's characteristics are production of plenty of new knowledge and appearance of lots of new products [3]. Its original power is creation and spillover of new knowledge. In essence, all the activities in an innovation cluster are related closely with knowledge production, knowledge spillover, and application of knowledge. A university takes scientific research as its mission, as well as it's the main producer and the key provider of knowledge for innovation cluster.

Universities have natural comparative advantage in production of knowledge within an innovation cluster. But commercial application of knowledge is mainly depended on another subject of the cluster, which is enterprise, to complete. Natural infiltration and overflowing of knowledge in universities cannot satisfy definite quality and speed of knowledge transfer that the development of innovation clusters needs. Therefore, it requires that universities must spread knowledge more actively and efficiently, and make sure the aim and construct proper mechanism. So university is also a spreader of knowledge. The construction of this mechanism creates a path to realize universities' functions and promotes the value of universities in an innovation cluster.

Potter thinks that the core competitive advantage of an organization derives from culture [4]. And Drucker also points that culture is one decisive production factor predominantly [5]. Fundamentally speaking, the success of Silicon Valley benefits from its particular culture, institution and environment [6]. As one of missions of universities, cultural inheritance and innovation indicates that universities play the role as an advocate of innovation culture, and build innovative atmosphere to inspire a large number of innovation emerging.

To sum up, this paper argues that the main functions of universities in an innovation cluster include knowledge production, knowledge dissemination and advocating innovation culture.

\section{The Realization Mechanism of Knowledge Production in Universities}

The process of products production is the whole process which includes steps from input of raw materials to the formation of finished products [7]. Acquisition and processing of the raw materials, as well as finishing products are the main representative stages among these steps [8]. The raw materials are knowledge, the knowledge to be processed is scattered, and the finished part is new knowledge produced by universities during production process of new knowledge. So we divide the process of knowledge production into three stages, including knowledge acquisition, knowledge process and knowledge formation [9]. As one of the main subjects in knowledge production of innovation clusters, universities essentially have scientific research talents who are skilled at creation of knowledge and rich knowledge resources carried by the talents. Hence the knowledge stock that universities have already is the initial factor of knowledge production which affects the level of new knowledge production. The stages including Knowledge acquisition, knowledge process and knowledge formation afterward are progressive gradually one by one. The previous stage affects the next stage. At the 
same time, knowledge accumulated in every step of knowledge production process increases the knowledge stock in universities, as shown in Figure 1.

Knowledge stock in universities consists of explicit knowledge produced by scientific researchers and tacit knowledge accumulated in their research experiences and contained in their research abilities. Their knowledge accumulation lays the foundation for making a breakthrough in their own research area [10], which represents their level of scientific research. So the knowledge stock in universities is the key point to the quality of new knowledge produced by universities. The two ways to change knowledge stock in universities are introducing external talents and cultivating internal talents. External talents can bring fresh viewpoints and experiences and make the existing knowledge stock abundant so that broaden the breadth of knowledge. Especially study and work experiences from people going abroad could help them grasp correctly the stage of development and future direction in one science field [10]. Cultivating internal talent scan explore potential innovative talents so that they would inherit and develop knowledge advantage in universities and extend the depth of universities' knowledge. Universities could retain and absorb talents inside and outside, and achieve optimization and expansion of knowledge stock through the design and implementation of policy.

Knowledge acquisition is a process to define the research problem and collect information. Knowledge attained includes two kinds of knowledge: one is knowledge related with the current market demand and technology situation, which are got by contact and communication with enterprises, the frequency, methods and level of universitiesindustry relations determines universities' understanding to realistic demand and affect whether universities can select the research direction having more market value further; the other is knowledge of academic frontier, which is attained by searching academic papers and monographs in the field through database, academic conference and so on and help researchers make clear their own research questions and research value in order to design a research route with more innovative and practical value.

Knowledge processing is based on the knowledge acquisition phase. Researchers make use of laboratories, equipments, instruments and research base and so on to dig, transfer, sift, integrate and reconstruct the knowledge has been attained before [11]. The results of knowledge processing directly affect the quality of output, which is the

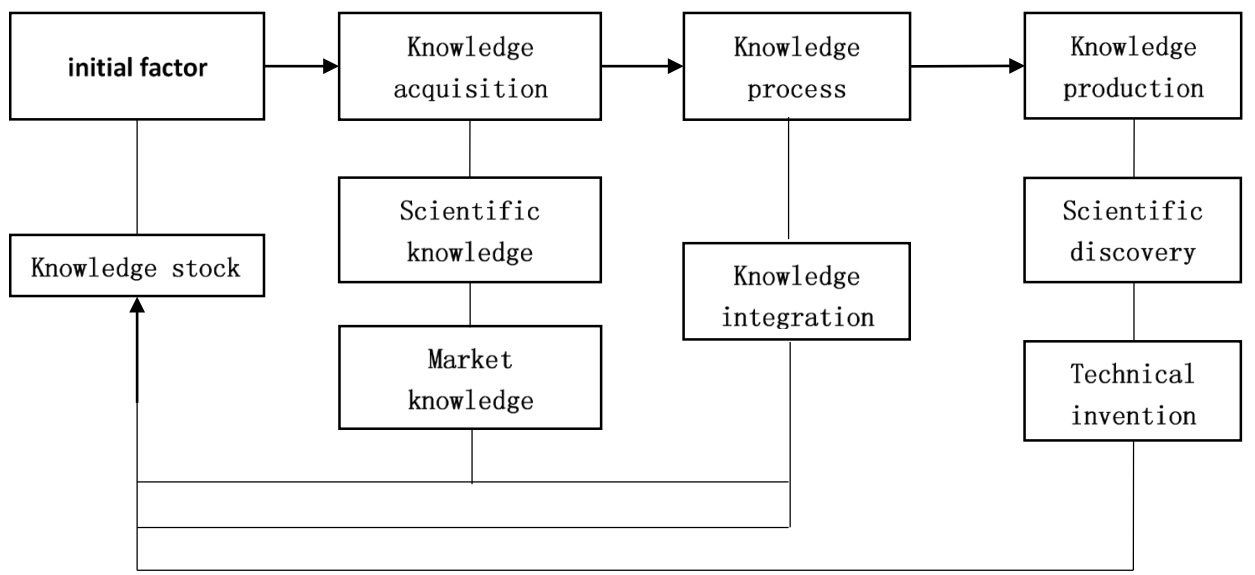

Figure 1. The implementation mechanism of knowledge production in universities. 
key step of knowledge production and determined by researchers' research capacity and their teams' collaboration ability. During this process, researchers form their own cognition and the research results basically have a prototype.

Knowledge production is the stage to complete and form the final achievement of scientific research, which is realized through coding research results and researchers' thoughts. The achievement can be divided into scientific discovery and technical invention. Scientific discovery is the form of public ownership and its reward system is based on non-market mechanism, including papers and monographs. However technical invention is private in forms of patents and its reward system is based on market mechanism [12]. It will form an incentive mechanism of researchers' knowledge production through constructing a reasonable assessment and protection system for scientific research achievements, which could strengthen the scientific research personnels' initiative and enthusiasm in knowledge production.

\section{The Realization Mechanism of Knowledge Propagation in Universities}

As the main source of knowledge production in innovation clusters, the breadth and depth of knowledge that universities own are both greater than that in enterprises from the view of knowledge potential. As a result, the knowledge potential in universities is overtop enterprises partly and has tendency and ability to spread the knowledge to enterprises. At the same time, universities' own nature and their function of social service decide their responsibility to promote the development of society. Universities show their willing to improve their speed and quality to spread knowledge under the situation that competition in innovation is increasingly intensifying.

Knowledge propagation can be divided into two kinds including conscious and unconscious knowledge propagation. Fallah and Ibrahim [13] put forward that knowledge spillover is knowledge spreading unconsciously, and knowledge transfer means knowledge communication between persons or organizations consciously. As two forms of knowledge dissemination, they both promote the development of innovation clusters. As one of the main functions of universities in cultivating innovative clusters, the specific implementation mechanism of knowledge propagation is shown in Figure 2.

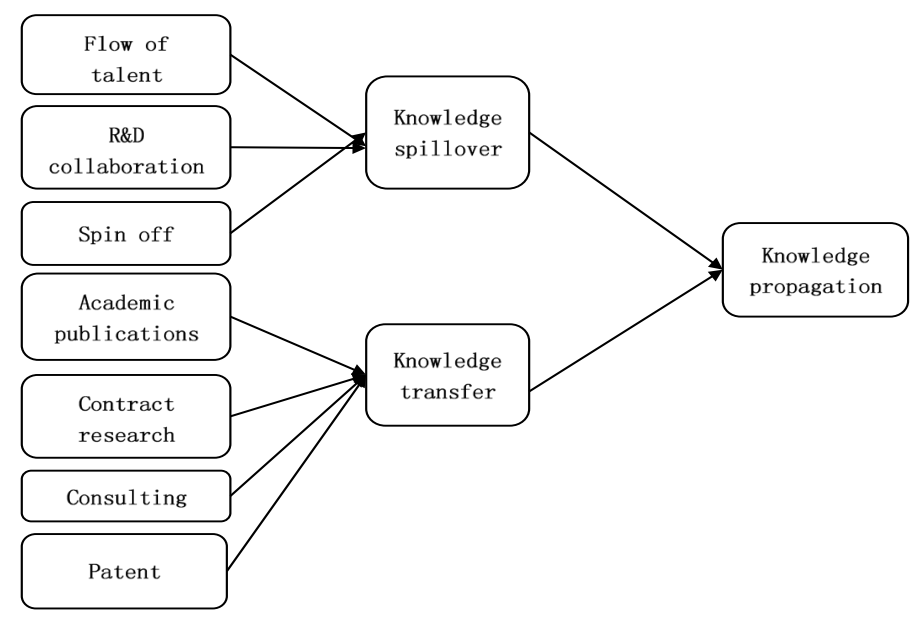

Figure 2. The implementation mechanisms of knowledge propagation in universities. 


\subsection{Knowledge Spillover in Universities}

As public goods, knowledge has characters of non-competitiveness and non-exclusiveness in a certain extent. So knowledge spillover in universities means that knowledge flows from universities into companies unconsciously through informal contacts and communication between universities and industry. However, knowledge spillover has space limitation and personal contacts within certain spatial range make it possible. So it is an important reason for the appearance of innovation clusters [14]. Knowledge spillover in universities is a form to spread knowledge without explicit reward and it decreases the huge costs for hunting and attaining knowledge of firms and promotes commercialization of knowledge.

Because knowledge spillover is an unconscious process, its main form is universityindustry communication aimed at tacit knowledge which is difficult to code. It includes flow of talent, R \& D collaboration and spin-off. Universities' function of talent training ensure its rich human resources and talents have plenty of tacit knowledge accumulated in the environment of universities. So talents could become medium that let knowledge flow from universities to companies through talents flow in different space and make connections with the environment around them. $\mathrm{R} \& \mathrm{D}$ collaboration is a kind of partnership between universities and industry because of knowledge complementarity of them, especially university-industry strategic alliance based on long-term and stable cooperation. During R \& D collaboration, researchers from universities and technical persons from firms exchange their knowledge by informal contacts and attending academic conferences so that to realize knowledge spillover of universities. Spin-offs are science and technology enterprises which come into being from universities, are based on scientific research achievements, and are founded by college teachers and researchers [15]. Entrepreneurs of universities are from colleges and have innumerable links with universities. During the process of startup, they communicate and cooperate constantly with organizations outside universities. And other companies in clusters will learn from spin-offs on account of their advantages in knowledge. So Spin-off becomes another way for knowledge spill over.

\subsection{Knowledge Transfer in Universities}

Knowledge transfer is the basis and micro process of technology innovation activities for the main subjects of innovation clusters [16]. Knowledge transfer in universities means that universities actively participate in cluster innovation process and emphasize that universities consciously spread knowledge to enterprises. Usually researchers in universities carry out knowledge transfer for attaining academic resources or economic benefits. It takes relevant institution and policy support as premise and give return for knowledge output of universities via the form of market transactions based on contract spirit to encourage universities to transfer knowledge actively.

Initiative and pertinence of knowledge transfer in universities indicate that universities and industry come to an agreement on what knowledge to be transferred, how to transfer and what reward universities will get before universities decide to transfer knowledge. As a result, transferred knowledge in universities is mainly explicit knowledge, including publications, contract research, consulting and patent. Publications 
like papers and books are embodiment of achievements of universities' knowledge production and provide clues for enterprises to find valuable knowledge. Also they win more resources for academics in scientific assessment. Contract research is that enterprises entrust scientific projects to universities in the form of market agreement in order to solve problems that are difficult for them and decrease their costs in research. Consulting means that enterprises hire academics to transfer knowledge in universities to enterprises for solving their problems. Patenting is that universities transfer their technology achievements to enterprises with the help of technology transfer offices. That is one key form of knowledge transfer for universities.

\section{The Realization Mechanism of Advocate for Innovation Culture in Universities}

Innovation culture is about value, idea, behavior pattern and institutional system that inspire and promote innovative thoughts, behaviors and activities of individuals, organizations and regions come forth continually within innovation cluster. It contains scientific spirit, trust, tolerance for failure, cooperation, competition, openness, encouraging adventure and so on. It is the important supporting system of innovation system, strengthen the flow of knowledge between organizations and form coordination, reinforcement and communication mechanism of innovation [17].

As advocate for innovation culture, universities should firstly construct innovation culture in their own environment, form the atmosphere of innovation and encourage innovation. Secondly universities should practice actively innovation behaviors and set an example with innovation activities to influence and even change the culture in clusters. So we conclude that universities' role of advocate for innovation culture works through nurturing innovation culture and demonstration of innovation culture. Its realization mechanism is shown in Figure 3.

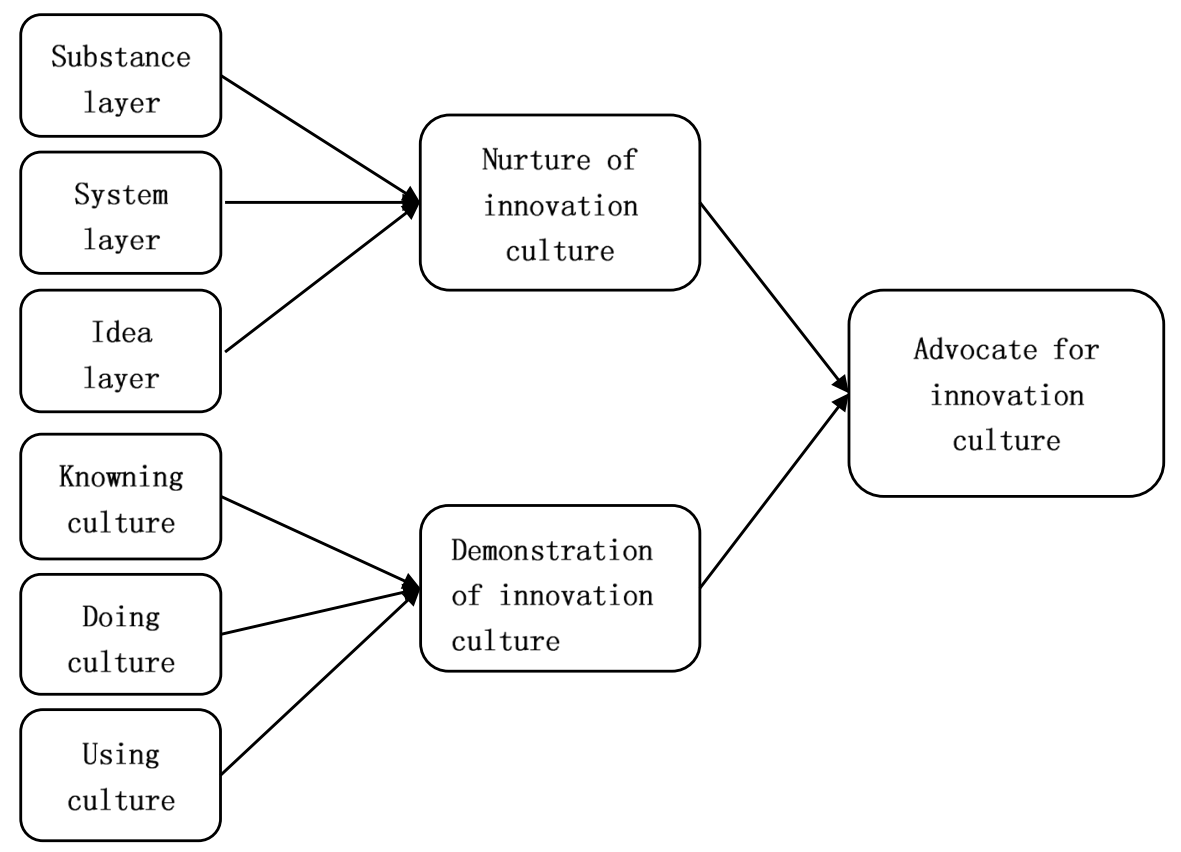

Figure 3. The realization mechanism of advocate for innovation culture in universities. 


\subsection{Nurture of Innovation Culture}

Culture is a kind of value idea and behavior pattern formed by humans in specific environment. Nurture of innovation culture needs to build environment of innovation to drive individuals to form innovative concepts and behaviors and they are accumulated gradually to generate innovation culture. We could construct innovative atmosphere from the view of structure of culture in order to provide motivation for individuals to innovate actively.

Innovation culture can be divided into idea layer, system layer and substance layer lengthways. The outermost layer is the substance layer and means infrastructures and institution buildings that could be observed visually, which makes occurrence of innovative behaviors possible and convenient. The middle layer is the system layer that includes rules and regulations, management mode and so on. They guide and inspire innovative behaviors. The core layer is the idea layer, which is the reflection of innovation culture in value orientation and ideology. It is steady and secluded. So it often has a leavening influence for innovation.

To nurture innovation culture, in the substance layer, universities should attend all kinds of university-industry cooperation, construct and perfect institutions and facilities for innovation. For example, university science park should be improved, or business incubator should be introduced. At the same time, specialized organizations devoted to patent management should be constructed inside universities. They all help perfect substance basis of innovation culture. In the system layer, universities should reform management and evaluation system for science research and education. Also universities need to devolve executive power appropriately, then construct management mechanism that is in accordance with science and education development as well as evaluation index that takes social contribution as guidance so that to give more freedom for academics in research and teaching. In idea layer we should assimilate innovation culture into university culture by constructing network of innovation culture, setting up innovative pioneer as good examples, forming etiquette and ceremonies of innovation, expanding slogans and banners about innovation.

\subsection{Demonstration of Innovation Culture}

Demonstration of innovation culture in universities plays an exemplary role for other subjects in innovation clusters. It potentially delivers culture concepts of innovation, entrepreneurship, collaboration and openness within innovation clusters by the ways of talent training, scientific research, social services in the process of knowledge creation and knowledge propagation.

Innovation culture is mainly reflected in activities of knowledge creation, commercialization, consumption and diffusion. So innovation culture can be divided into knowing culture, doing culture and using culture breadth wise. Knowing culture means scientific spirits of being brave in exploring and discovering truth, doing culture means entrepreneurship aimed at knowledge commercialization and industrialization as well as culture concept of cooperation and trust. Using culture means culture about knowledge and products using, consumption and diffusion [18].

Making universities as a research object, knowing culture is an ability that universi- 
ties always own and are different with other subjects of cluster in its demonstration of innovation culture. Because of scientific spirits of exploring truth and discovering new knowledge, academics perseverely create new knowledge that promotes the development of human society. Universities actively take part in innovation activities and promote the process of knowledge commercialization. They turn their knowledge into products in the market through entrepreneurship and creating spin-offs. It is one way to participate in knowledge transfer directly. Also universities cooperate with firms for innovation and they communicate with each other based on trust so that to transfer knowledge to firms and realize commercial value of knowledge. It is one way to participate in knowledge transfer indirectly. For using knowledge, talent training of universities makes academics impart their knowledge to students and train innovative talents. And then it promotes flow of new knowledge and innovation spirits in innovation clusters through flow of talents. So it realizes transmission of innovation culture in innovation clusters.

\section{Conclusions and Implications}

This paper analyzes the functions of universities in innovation clusters and their implementation mechanisms. And it concludes from theoretical research and practical implications that if we decide to nurture an innovation cluster with vitality of sustainable development, we must pay attention to and give rein to the functions of knowledge production, knowledge propagation and advocate for innovation culture of universities. Also the research results can act as guidance and reference for follow-up empirical research.

Also we could find that the three functions of universities in innovation clusters are not independent, but overlap, interrelate and coordinate with each other. In the future research, we could explore their relations further and make clear how they coordinate with each other in order to understand universities' functions in innovation clusters better.

\section{References}

[1] Fan, S. and Li, J.J. (2011) Innovation System of South Korea Mode: The Role of URIs and the Cluster. Science of Science and Management of S. \& T., 9, 73-79.

[2] Clark, K. (2008) The Uses of the University. Peking University Press, Beijing.

[3] Xu, X.M. (2011) Cultural Inheritance Innovation: The Establishment of the University's Fourth-Largest Function. Higher education in China, 10, 10-11.

[4] Samuel, H. and Lawrence, H. (2002) The Important Role of Culture-How Values Affect Human Progress. Cheng, K.X., Trans., Xinhua Publishing House, Beijing, 43-61.

[5] Drucker, P. (1999) Management during Time of Changes. Zhao, G.C., Trans., Shanghai Translation Publishing House, Shanghai.

[6] Annapolis, S. (1999) Region Advantage-Silicon Valley and Route 128 Culture and Competition. Cao, P. and Yu, G., Trans., Shanghai Far East Publishing House, Shanghai, 5.

[7] Chen, R.Q. and Ma, S.H. (2011) Production and Operation Management. Higher Education Press, Beijing.

[8] Zhang, S. (2011) Research on Production Process Management of Shanghai Philips Lighting Products. Master Degree Theses, East China University of Science and Technology, 
Shanghai.

[9] Li, B.Z., Luo, X.F. and Zhang, Y. (2014) Study on Knowledge Production Mechanism of Enterprise Original Innovation with Industry-University-Research Cooperative ModeThe Empirical Study Based on Enterprises in High-Tech Fields. Management Review, 7, 82-91.

[10] Chen, J. and Wang, J.H. (2015) Original Innovation in Basic Research of Domestic Universities: Multiple Case Study. Studies in Science of Science, 4, 490-497.

[11] Wu, F.Y., Chen, G.H. and Cai, Y.H. (2011) Research on Relationship among Network of Industry Cluster, Knowledge Integration and Innovation Performance. Chinese Journal of Management Science, 19, 114-120.

[12] Yuan, Z.G. (1999) Research on Knowledge Production and Consumption. Economic Research, 6, 59-65.

[13] Hosein Fallah, M. and Sherwat, I. (2004) Knowledge Spillover and Innovation in Technological Clusters. http://www.stevens.edu

[14] Song, Q., Han, B.T. and Wang, Z.C. (2010) The Life Cycle Research of Innovative Clusters Based on Knowledge Spillover Entropy. Science of Science and Management of S. \& T., 3, 68-71.

[15] Pang, W. and Ding, Y.L. (2013) Empirical Study on Spin-Off Capabilities of Research Universities in China. Forum on Science and Technology in China, 2, 45-52.

[16] Wang, B.F. and Liu, F. (2010) Model and Characteristics of Knowledge Transfer within Innovative Clusters. Science \& Technology Progress and Policy, 27, 135-138.

[17] Gu, S.Z., Li, J.J. and Zheng, L.Y. (2007) Study on University-Industry and Reconstruction of Innovation Culture. China Soft Science, 2, 41-48.

[18] Wu, J.X. (2011) A Comprehensive Framework to Understand Innovation Culture and Its Policy. China Soft Science, 5, 65.

Submit or recommend next manuscript to SCIRP and we will provide best service for you:

Accepting pre-submission inquiries through Email, Facebook, LinkedIn, Twitter, etc. A wide selection of journals (inclusive of 9 subjects, more than 200 journals)

Providing 24-hour high-quality service

User-friendly online submission system

Fair and swift peer-review system

Efficient typesetting and proofreading procedure

Display of the result of downloads and visits, as well as the number of cited articles

Maximum dissemination of your research work

Submit your manuscript at: http://papersubmission.scirp.org/

Or contact ojbm@scirp.org 